\title{
INFLUENCE OF PERMEATION ENHANCERS ON THE IN VITRO SKIN PERMEATION OF KETOROLAC TROMETHAMINE THROUGH EXCISED RAT SKIN: A MECHANISTIC STUDY
}

\author{
AFROOZ SAADATZADEH ${ }^{1,2}$, ANAYATOLLAH SALIMI $^{2 *}$, MOIEN ZAROONI ${ }^{3}$ \\ ${ }^{1}$ Department of Food and Drug Control, Faculty of Pharmacy, Jundishapur University of Medical Sciences, Ahvaz, Iran. ${ }^{2}$ Nanotechnology \\ Research Center, Department of Pharmaceutics, Ahvaz Jundishapur University of Medical Sciences, Ahvaz, Iran. ${ }^{3}$ Student Research \\ Committee, Ahvaz Jundishapur University of Medical Sciences, Ahvaz, Iran. E-mail: anayatsalimi2003@yahoo.com
}

Received: 07 December 2017, Revised and Accepted: 07 December 2018

ABSTRACT

Objective: Ketorolac tromethamine (KT) is considered as a member of Non-steroidal anti-inflammatory drugs that used as an analgesic and antipyretic agent. The main aim of this research was to investigate the effect of some herbal and chemical permeation enhancers on the in vitro skin permeability of KT.

Method: Ketorolac permeability experiments through rat skin pre-treated with some of permeation enhancers, namely urea, eucalyptus oil, olive oil, and menthol, were performed in fabricated Franz diffusion cells and compared with hydrated rat skin as control. The permeability parameters evaluated include steady-state flux (Jss), permeability coefficient (Kp), and diffusion coefficient (D). The penetration enhancers permeability enhancement mechanisms were investigated by comparing changes in peak position and their intensities of asymmetric (Asy) and symmetric (Sym) C-H stretching, $\mathrm{C}=\mathrm{O}$ stretching, $\mathrm{C}=\mathrm{O}$ stretching (Amide I), and C-N stretching of keratin (Amide II) absorbance using fourier transform infrared spectroscopy (FT-IR), as well as by comparing mean transition temperature (Tm) and their enthalpies $(\Delta \mathrm{H})$ using differential scanning calorimetery (DSC). KT permeability parameters through rat skin were evaluated with and without chemical enhancers such as eucalyptus oil, olive oil, menthol, and urea.

Result: The skin showed barrier for ketorolac permeability through the whole skin and that diffusion into the skin was the rate-limiting step for drug flux. Urea, eucalyptus oil, olive oil, and menthol were the most effective enhancers as they increased flux 0.02, 0.017, 0.016 , and 0.012 times and diffusion coefficient $0.079,0.194,0.129$, and 1.35 folds in comparison with hydrated skin, respectively.

Conclusion: FT-IR and DSC results showed lipid fluidization, extraction, disruption of lipid structure, and irreversible denaturation of proteins in the stratum corneum layer of the skin by permeation enhancers.

Keywords: Ketorolac tromethamine, Percutaneous absorption, Enhancers, Differential scanning calorimetery, Fourier transform infrared spectroscopy, Rat.

(C) 2018 The Authors. Published by Innovare Academic Sciences Pvt Ltd. This is an open access article under the CC BY license (http://creativecommons. org/licenses/by/4. 0/) DOI: http://dx.doi.org/10.22159/ajpcr.2018.v11i7.24162

\section{INTRODUCTION}

Permeation of drugs through the skin is the basis of transdermal delivery. Transdermal drug delivery is associated with some advantages such as controlled and continuous drug delivery which is important for drugs with short biological half-life and low therapeutic indices, first-pass intestinal and hepatic bypass, avoidance of gastrointestinal irritation which is common with oral medications, and facilitation of drug localization at target site [1].

Two main steps in skin permeation are partitioning and diffusion through the stratum corneum (SC) and viable epidermis, passage into the dermis, and finally, systemic absorption or penetration into deeper tissues. The greatest barrier to drug penetration is the SC, the outermost layer of the skin [2]. The SC poses a formidable challenge to drug delivery systems. Several approaches have been used to improve entry of drugs into lower skin layer and deeper tissues. Chemical and physical permeation enhancers have been designed to facilitate delivery of high drug concentrations across the skin into systemic circulation or deeper tissues.

The classes of enhancers used and the mode of action of these agents vary [3]. Increased drug diffused in the skin, SC lipid fluidization, and increase in thermodynamic activity of drug in the skin and vehicles, as well as the effect on drug partition coefficient, are the most common mode of action of chemical enhancers. Ketorolac tromethamine (KT) is a non-steroidal anti-inflammatory drug (NSAID) with molecular formula $\mathrm{C} 15 \mathrm{H} 12 \mathrm{NO} . \mathrm{C} 4 \mathrm{H} 12 \mathrm{NO} 3$ [4]. It is one of the most potent NSAIDs. Its analgesic and anti-inflammatory actions derive from a common mechanism which is the inhibition of the cyclooxygenase; however, additional mechanism of action has been proposed, including a participation of opioid receptors although it does not bind to these receptors [5]. It is indicated to treat moderate-to-severe pain, and it has been studied in a broad spectrum of pain states such as post-partum and post-operative arthritic pain, pain of trauma, severe dental pain, and renal, biliary colic, and cancer, abdominal and .gical pain [6]

To develop transdermal drug delivery systems, investigation of microstructure of intercellular or lipids in SC layer of skin is required. In the recent studies, organization of lipids and skin microstructure has been examined using various techniques including differential scanning calorimetry (DSC) and Fourier transform infrared spectroscopy (FT-IR) [7]

The FT-IR analysis of skin can be a practical tool for studying the interaction between chemical enhancers materials with SC that provides bands at different wave numbers. To recognize the mechanism by which the properties of enhancers/retardants change in a given vehicle, molecular studies of whole rat skin was carried out using DSC and FT-IR [8]

Several infrared spectral bands of the skin are attributed to vibration of protein and lipid molecules in the SC. 
The lipid vibration is a good index to evaluate the microstructure of the lamellar lipids form in the intercellular area in the SC layer. Some different spectral regions of the SC were expected to have various bands, - $\mathrm{CH} 2$ symmetric vibration (near $2850 \mathrm{~cm}^{-1}$ ) and -CH2 asymmetric vibration (near $2920 \mathrm{~cm}^{-1}$ ), and amide I (about $1650 \mathrm{~cm}^{-1}$ ) and amide II (near 1550 $\mathrm{cm}^{-1}$ ) stretching vibrations of SC protein have been reported. An increase in wave number and width of $-\mathrm{CH} 2$ stretching peaks is due fluidization of the SC lipids [9]. If the shift is to higher wavenumber (blueshift), it indicates SC membrane (lipid bilayer) fluidization that in change contribute to the disruption of the barrier properties that probably causes the substance permeation enhancement through the SC [10]. On the other hand, lipid groups are oriented again, a phenomenon that causes a shift to lower wave number (e.g., redshift) and strengthening of subcutaneous barrier properties which finally slows down the entrance of permeant through the skin [11]. If the penetration modifier performs by affecting on lipid pathway, the phase transition of the lipids is showed by increase/decrease in the band position (wavenumber) of the signals at 2920,2850 , and near $1738 \mathrm{~cm}^{-1}$ [12]. Thermal analysis methods such as DSC have been utilized to investigate thermal transitions in mammalian SC. The SC is the outermost layer of the epidermis and is primarily responsible for the skin's barrier function. The DSC technique is widely used for characterization the melting of lipids and the phase transition of lipid bilayers and protein denaturation in SC layer. To obtain more detailed information about lipid components and protein conformational stability of the whole skin rat treated with pure vehicle, a DSC study was programmed [13]. By comparing mean transition temperature (Tm) and enthalpies $(\mathrm{H})$, thermotropic behavior of treated skin was assessed. Any transition in Tm to lower degrees may be due to lipid disruption in bilayer and irreversible protein denaturation in SC. While, enthalpy decrease is generally related to lipid fluidization in lipid bilayers and protein-lipid complexes [14].

\section{MATERIALS AND METHODS}

\section{Materials}

KT was kindly donated by Caspian Tamin pharmaceutical company (Tehran, Iran). Eucalyptus oil (70\% 1,8-cineole) and olive oil were purchased from Barij essence company, Iran. Urea was purchased from Merck. Potassium phosphate monobasic and menthol were supplied by Sigma, Germany. Deionized water was made in our laboratories. The remaining chemicals used were of analytical grade [15].

\section{Animal studies}

For in vitro permeation studies, male Wistar rats (200-250 g) were used. Animals were euthanized under ether anesthesia. Abdominal hair was removed carefully with an electrical shaver followed by razor. The abdominal skin was excised and extraneous SC fat was removed. The skin thickness was determined using an electronic caliper. All animals were treated according to protocols and ethical approval was obtained from the Ethical Committee of the Ahvaz Jundishapur University of Medical Sciences. The same guideline as the National Academy of Sciences and published by the National Institutes of Health (US. Department of Health \& human services, office of laboratory animal welfare) were followed.

\section{Ketorolac assay}

Amount of KT was determined by ultraviolet spectroscopy method at wavelength of $\lambda_{\max }=322 \mathrm{~nm}[16]$.

\section{In vitro permeation study}

A diffusion cells was specially designed for permeation studies with an effective area of $3.37 \mathrm{~cm}^{2}$ and the receptor compartment had a $25 \mathrm{ml}$ capacity. The skin samples were hydrated before use and then placed between the donor and receptor compartments of the cells while epiderm was facing toward the donor medium. The donor compartment was filled with KT $(2 \% \mathrm{w} / \mathrm{v})$ solution dissolved in distilled water and the receptor chamber was filled with phosphate buffered saline (PBS) ( $\mathrm{pH}$ 7). The diffusion cell was placed and clamped in a water bath at $37 \pm 0.05^{\circ} \mathrm{C}$ on a magnetic stirrer with a heater. The receptor media was stirred continuously at $300 \mathrm{rpm}$. About $2 \mathrm{ml}$ of the receptor medium was collected at $0.5,1,2,3,4,5,6,7,8$, and $24 \mathrm{~h}$ intervals and was immediately replaced by an equal volume of fresh buffer. The collected samples were filtered and the amount of permeated ketorolac was determined as mentioned above [17].

\section{Pre-treatment of skin samples}

Skin samples were fully hydrated and pre-treated by addition of $2 \mathrm{ml}$ of permeation enhancers (Eucalyptus oil [containing $70 \%$ 1, 8-cineole], olive oil urea, and menthol) on the skin surface for $4 \mathrm{~h}$. In the donor phase, the donor and receptor compartments were rinsed with water and were filled with ketorolac aqueous solution and PBS (pH 7), respectively. A fully hydrated sample were used as controls and to avoid experimental errors from biological variability, a piece of each skin samples has been used as its own control [18].

\section{Data analysis}

The total amount of ketorolac diffused through the receptor based on the unit area of the diffusion surface was calculated and plotted as function of time. Steady state flux $\left(\mathrm{mg} / \mathrm{cm}^{2} . \mathrm{h}\right)$ was obtained from the linear parts of permeation curve slope. Permeation coefficient (Kp, $\mathrm{cm} / \mathrm{h}$ ) of Ketorolac through the skin were obtained using the following formula.

Equation 1: [19]

$\mathrm{Kp}=\mathrm{Jss} / \mathrm{Cv}$

Where Jss is the steady state flux and $\mathrm{Cv}$ is the initial concentration of ketorolac in receptor compartment.

Enhancement ratios (ERs) were obtained using the following formula. $\mathrm{ER}=$ permeability parameter after treatment/permeability parameter before treatment. One-way ANOVA test was used to compare the results and $p<0.05$ was considered as statistically significant. Least-square linear regression method was used for analysis of correlation and correlation coefficient was determined by Student's t-test. MINITAB software version 17.0 was used to perform all statistical analysis.

\section{DSC}

The effect of chemical permeation enhancers on the structure of the whole skin was investigated using a DSC (Mettler Toledo DSC1system) system. The skin samples were completely hydrated and soaked in chemical permeation enhancers for $4 \mathrm{~h}$. The excess permeation enhancers were removed and the samples were sealed hermetically to prevent any evaporation. Pre-treated skin samples $(6-10 \mathrm{mg})$ were placed in an aluminum pan and sealed and another empty pan was used as the reference. The samples were heat treated $\left(20-200^{\circ} \mathrm{C}\right)$ repeatedly at a rate of $5^{\circ} \mathrm{C} / \mathrm{min}$. All experiments were conducted three times and every time the DSC analyzer was calibrated with indium standard [21].

\section{FT-IR studies}

The skin samples were treated with permeation enhancers (urea, menthol, eucalyptus oil, and olive oil) for $24 \mathrm{~h}$. Vacuum dried $\left(650 \mathrm{~mm} \mathrm{Hg}, 25 \pm 1^{\circ} \mathrm{C}\right.$ ) for $30 \mathrm{~min}$ and desiccated to remove any traces of permeation enhancers [19]. The samples were then scanned by FT-IR (Uker, Vertex70, Germany) in the range of $4000-500 \mathrm{~cm}^{-1}$ [22]

\section{RESULTS AND DISCUSSION}

\section{Effect of enhancers on ketorolac skin permeability}

The permeability parameters were measured after exposure to enhancers and were compared with control. The amount of ketorolac permeated after exposure to each enhancer is presented in Table 1 and Fig. 1. Table 1 shows the effect of enhancers on ketorolac permeability as $\mathrm{ER}_{\text {flux }}$ (ratio of drug flux before and after exposure to enhancer) and $\mathrm{ER}_{\mathrm{D}}$ (drug diffusion before and after exposure to enhancer) in comparison with control [12].

Hydrated skin saturated in aqueous solution of ketorolac as donor phase without exposure to enhancer was used as control. These results 
suggest that permeation enhancers (eucalyptus oil, olive oil, urea, and menthol) increased ketorolac flux and diffusion coefficient significantly, and the difference was statistically significant $(p<0.05)$. Urea caused increased ketorolac flux by 0.02 -fold in comparison with control which was higher than the change observed after eucalyptus oil ( 0.017 fold), olive oil ( 0.012 fold), and menthol ( 0.016 fold).

The diffusion coefficient was significantly different coefficient $(\mathrm{p}<0.05)$, after treatment with each enhancer; with olive oil, causing the highest enhancement ( 1.35 fold) followed by eucalyptus oil ( 0.194 -fold), menthol $(0.129$-fold), and urea $(0.079)$. No significant difference $(p<0.05)$ was observed between enhancers on permeability coefficient (P) after treatment $P$ of all enhancers were in range $(0.0001-0.0002 \mathrm{~cm} / \mathrm{h})$.

These results suggest that these enhancers were mainly facilitating the drug diffusion into the skin. The eucalyptus oil used consisted of $75 \%$ 1,8-cineole and olive oil which both are cyclic terpenes that act by making a liquid pool in SC and also by disrupting the lipid structure in SC. Thus, these both enhancers will increase the diffusion coefficient of both polar and non-polar drugs in the membrane [23].

Urea and its derivatives have keratolytic properties that could explain the slight enhancement in penetration of drug observed following treatment with these agents. Urea can also increase the water content in SC and act as moisturizing agent to create a hydrophilic diffusion channels within the barrier [24] which could be another explanation for the observed effect. They also can act by disrupting the skin lipids [25] structure and can be used as a permeation enhancer in various solvents to affect the skin.

Urea can act by assisting hydration of the SC and formation of hydrophilic diffusion channels within the barrier to increase the transdermal permeation. Cyclic urea is composed of a polar parent moiety and a long-chain alkyl ester group. They are biodegradable and non-toxic. Therefore, the observed enhancement in permeation could be due to both hydrophilic activity and lipid disruption mechanisms [26].

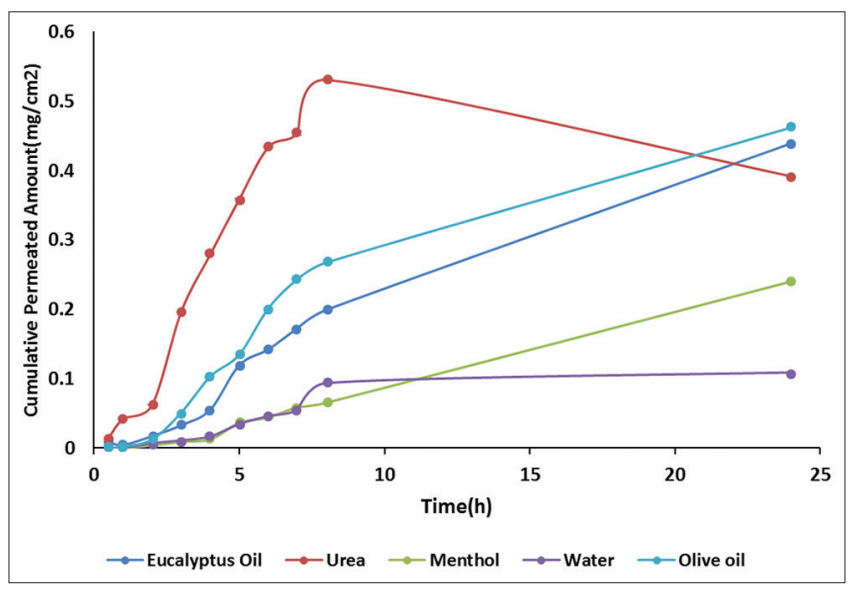

Fig. 1: The amount of ketorolac permeated from various pretreatment rat skins with various chemical enhancers
DSC

To examine the thermotropic properties of treated skin, mean transition temperature $(\mathrm{Tm})$ those enthalpies $(\Delta \mathrm{H})$ were used. The Tm and $\Delta \mathrm{h}$ are shown in Table 2 and the thermograms are shown in Fig. 2.

Tm1 of 67.5 and Tm2 of 1121 were achieved for hydrated rat skin which suggested the melting of lipids and irreversible denaturation of intracellular keratin. Any negative change in $\mathrm{Tm}$ could be because of lipid disruption in bilayer and irreversible denaturation of protein in SC layer. While a decrease in enthalpy is usually due to lipid fluidization in the lipid bilayers and also protein-lipid complexes. The human dermal DSC graph has been reported by Kaushik et al. and three endothermic transition peaks of 59-63 5 (Tm1), 75-82 7 (Tm2), and 99.5-120 9 (Tm3) have been observed [27]. They have proposed that the Tm1 could be due to a transformation of lipid from lamellar form to a disorder state, Tm2 is related to protein-lipid complex or a disruption in lipids polar head groups, and Tm3 could happen while proteins undergo irreversible denaturation. When the skin was pre-treated with menthol, the thermograms showed reduction in $\Delta$ in and $\Delta \mathrm{a} 2$. There was an increasing in $\mathrm{Tm} 2$ when it was compared with hydrated rat skin. Moreover, Tm1 was not observed after treatment with menthol. These results suggest that menthol could potentiate a structural change, increase the fluidity of lipids in intracellular space, disrupt lipids at bilayer, and also to irreversibly denature proteins in SC. The DSC results produced following the pre-treatment of skin with eucalyptus oil revealed a reduction in $\operatorname{Tm} 1$ and increase in $\operatorname{Tm} 2, \Delta 2$, and $\Delta$ nd in compared to the value of hydrated rat skin. This results show that the eucalyptus oil is capable of increasing the skin permeation by more than one mechanism. The eucalyptus oil could act either by disruption of lipids in bilayer or by irreversibly denaturing the SC proteins. After pre-treatment of skin with urea, the thermograms revealed that both $\operatorname{Tm} 1$ and $\operatorname{Tm} 2$ were lifted to lesser melting points. It was also observed that the $\Delta$ th was also increased in comparison with control samples. These observations indicate that urea can cause a reorientation in the lipid bilayer of SC layer. Moreover, a reduction in the value of $\Delta$ la was observed when it was compared to control value which could indicate a fluidity in the lipid-protein complex od DC layer [28].

When the skin was pre-treated with olive oil, the thermograms showed a reduction in $T m 1$ while $T m 2, \Delta 2$, and $\Delta$ nd showed increasing shift in comparison to the value of hydrated rat skin. This finding indicates that the olive oil can increase the skin permeation by two probable mechanisms; disruption of lipids in bilayer and irreversible denaturation of proteins present in SC layer [28].

\section{FT-IR spectroscopy}

The spectral analysis of samples based on any changes in the position of peak and also the m intensities from $4000 \mathrm{~cm}^{-1}-500 \mathrm{~cm}^{-1}$ has been presented at Fig. 3 and Tables 3-5. A positive shift to a higher wavelength number known as blueshift is indicative of a fluidization in the lipid bilayer of SC layer which could contribute to the disruption of the barrier properties that could potentially result in enhancement of substance permeation into the SC layer [29]. On contrast, if the lipid groups are reoriented, it results in a negative shift to a lower wavelength number known as redshift. The redshift can strengthen the barrier properties of SC layer that could result in reduction of passage of any permeant in and out of the skin.

Table 1: Permeability parameters after pre-treatment with permeation enhancers compared with control (Mean $\pm S D, n=3$ )

\begin{tabular}{|c|c|c|c|c|c|c|c|}
\hline Enhancer & $\begin{array}{l}\text { Jss } \\
\left(\mathrm{mg} / \mathrm{cm}^{2} . \mathbf{h}\right)\end{array}$ & $\operatorname{Dapp}\left(\mathrm{cm}^{2} / \mathrm{h}\right)$ & $P(\mathrm{~cm} / \mathrm{h})$ & Tlag (h) & ERflux & ERD & ERp \\
\hline Control & 0.0103lrility & $0.034042 \pm 0.0012$ & $0.0001 \pm 1.77$ & $1.5918 \pm 0.0605$ & - & - & - \\
\hline Menthol & $0.0166 \pm 0.0002$ & $0.129 \pm 0.041$ & $0.0002 \pm 3.54 \mathrm{E}-06$ & $0.441 \pm 0.141$ & $1.6116 \pm 0.0053$ & $3.777 \pm 1.073$ & $1.6116 \pm 0.0053$ \\
\hline $\begin{array}{l}\text { Eucalyptus } \\
\text { oil }\end{array}$ & $0.017 y p$ & $0.194 \pm 0.040$ & $0.00022 \pm 0$ & $0.28522 \pm 0 \mathrm{~s}$ & $1.71822 \pm 0 \mathrm{~s}$ & $5.682 \pm 0.981$ & $1.71822 \pm 0 \mathrm{~s}$ \\
\hline Urea & $0.02022 \pm 0 \mathrm{~s} \mathrm{o}$ & $0.07922 \pm 0 \mathrm{~s}$ & $0.0002 \pm 4.4194 \mathrm{E}-06$ & $0.6852 \pm 4.41$ & $1.995 \pm 0.0617$ & $2.349 \pm 0.201$ & $1.995 \pm 0.0617$ \\
\hline Olive oil & $0.0127 \mathrm{oi}$ & $1.35084 \pm 0.52101$ & $0.00011 \mathrm{i}$ & 0.04331il4194 & $1.233 \pm 0.0169$ & $40.001 \pm 16.825$ & $1.233 \pm 0.0169$ \\
\hline
\end{tabular}

SD: Standard deviation 


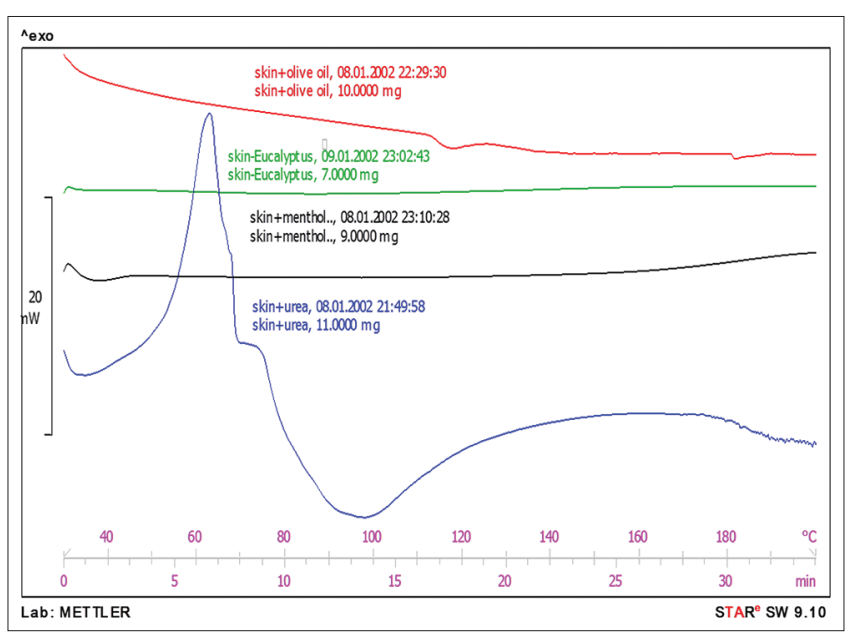

Fig. 2: Differential scanning calorimetery thermograms of pretreatment skin rat wit eucalyptus oil $(-)$, olive oil $(-)$ menthol $(-)$ and Urea $(-)$.

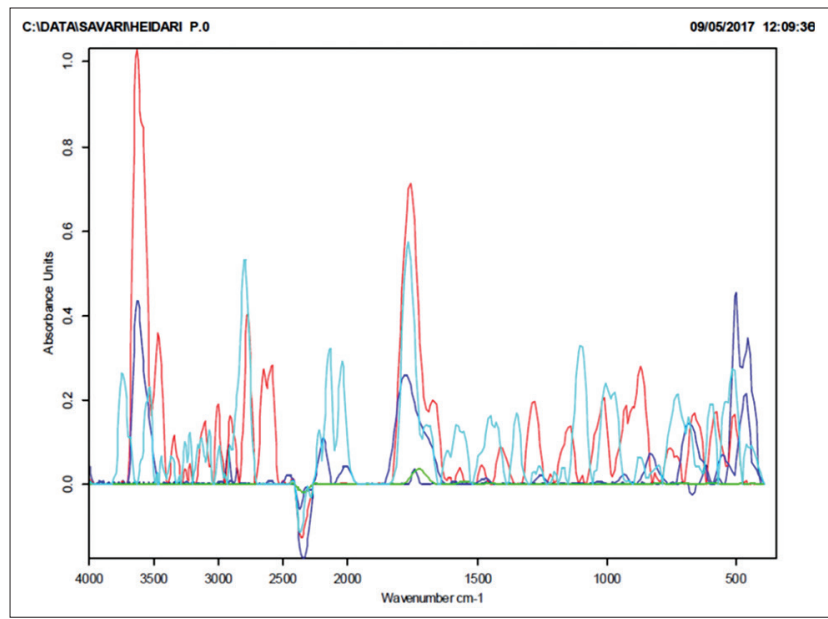

Fig. 3: Fourier transform infrared spectroscopy spectra of pretreatment skin rat wit eucalyptus oil $(-)$, olive oil $(-)$, menthol $(-)$, and urea $(-)$
After pre-treatment of rat skin with menthol, the spectra showed a change in height of the peak as well as the wavelength value. A wavelength number of $2908.58 \mathrm{~cm}^{-1}$ was observed after pretreatment of skin with menthol indicating a negative shift or a redshift. This result suggests that a reorientation of lipid groups within the SC layer has occurred that could potentiate the barrier function of SC layer. A blueshift was observed in $1690.2 \mathrm{~cm}^{-1}$ band after pre-treatment of skin with menthol which indicates to grow thin of hydrogen bonds inside the lipid structure. Results also showed at the peak heights of $1642.5 \mathrm{~cm}^{-1}$ and $1535.9 \mathrm{~cm}^{-1}$ wavelength values after pre-treatment of skin with menthol that could suggest an irreversible protein denaturation in SC layer.

After pre-treatment of rat skin with eucalyptus oil, the FT-IR spectra showed a loss of wave lengthvalue and a complete reduction (100\%) of height of peak at the $2915.13 \mathrm{~cm}^{-1}$ wavelength value and blueshift at the peak height of 2840.74 and $1690.2 \mathrm{~cm}^{-1}$. These findings indicate that eucalyptus oil acts primarily by engaging with lipids and proteins present in SC layer and can enhance skin permeation. After pretreatment of rat skin with eucalyptus oil, also, a relative redshift was observed in $1642.58 \mathrm{~cm}^{-1}$ and a blueshift in $1535.9 \mathrm{~cm}^{-1}$. These findings demonstrate that the eucalyptus oil is primarily engage with lipids and proteins present in SC layer [30].

Following the pre-treatment of rat skin with urea, the FT-IR spectra revealed redshift in peak height of the wavelengths of 2915.13 and $2840.7 \mathrm{~cm}^{-1}$, a blueshift in $1690.2 \mathrm{~cm}^{-1}$, and a $100 \%$ reduction and complete disappearance of peak height of the wavelengths of 1642.58 and $1535.9 \mathrm{~cm}^{-1}$. These results suggest that the urea can reorient of lipid groups within the SC layer and weaken of hydrogen bonds inside the lipid structure. FT-IR values after pre-treatment of rat skin with urea were agreement to that of DSC finding that indicates primarily mechanism of urea was on proteins present in SC [31].

The FT-IR results following pre-treatment of rat skin with olive oil showed blueshift in 2915.13, 2840.74, and $1690.2 \mathrm{~cm}^{-1}$ that indicate olive oil can primarily engage with lipids present in SC layer and causes to lipid fluidization. The FT-IR spectra also showed complete reduction (100\%) and loss of wavelength values at 1643.5 and $1535.9 \mathrm{~cm}^{-1}$. These results suggest that olive oil is capable to change the structure of lipids and denature irreversibly of intracellular keratin in the SC layer [31].

Table 2: Effect of permeation enhancer on the thermal properties of Exised rat skin (mean $\pm S D, n=3$ )

\begin{tabular}{llll}
\hline Enhancers & $\mathbf{T m}_{\mathbf{1}}$ & $\mathbf{T m}_{\mathbf{2}}$ & $\mathbf{\Delta H}_{\mathbf{1}}$ \\
\hline Control (water) & $67.5 \pm 2.1$ & $112 \pm 6.6$ & $-7.01 \pm 0.4$ \\
Eucalyptus & $37.5 \pm 0.1$ & $120.1 \pm 0.1$ & $-0.787 \pm 0.001$ \\
Urea & $38 \pm 0.2$ & $88 \pm 0.3$ & $-2.39 \pm 0.01$ \\
Olive oil & $42.5 \pm 0.5$ & $116 \pm 0.4$ & $-1.762 \pm 0.002$ \\
Menthol & - & $121 \pm 0.1$ & 0 \\
\hline
\end{tabular}

Tm1: Mean transition temperature of lipids, SC Tm2: Mean transition temperature of irreversible denaturation of intracellular SC keratin, $\Delta \mathrm{H} 1$ : Transition enthalpy of lipid phase SC $\triangle \mathrm{H} 2$ : Transition enthalpy of keratin phase SC. SD: Standard deviation

Table 3: Decrease in mean peak height $( \pm S D)$, compared with control (hydrated skin) of $\mathrm{C}=0$ stretching (Amide I) and C-N stretching of keratin (Amide II) absorbance of abdominal hydrated whole skin rat following treatment with different enhancers (Mean $\pm S D, n=3$ )

\begin{tabular}{|c|c|c|c|c|c|c|}
\hline \multirow[t]{2}{*}{ Vehicle } & Asymmetric & C-H stretching & Symmetric & C-H stretching & $\mathrm{C}=0$ stretching & Of lipid ester \\
\hline & Peak height & $\% \mathrm{D}$ & Peak height & $\% \mathrm{D}$ & Peak height & $\% \mathrm{D}$ \\
\hline Control & 0.395 & - & 0.242 & - & 0.015 & - \\
\hline Eucalyptus & 0 & 100 & 0.001 & 99.58 & 0.038 & Not seen \\
\hline Menthol & 0.242 & 38.73 & 0.434 & Not seen & 0.864 & Not seen \\
\hline Olive & 0.104 & 73.67 & 0.043 & 82 & 0.041 & Not seen \\
\hline Urea & 0.021 & 94.68 & 0.023 & 90.42 & 0.327 & Not seen \\
\hline
\end{tabular}

$\%$ Decrease in peak height $(\% \mathrm{D})=$ (peak height from untreated whole skin - peak height from solvent treated whole skin)/peak height from untreated whole skin $\times 100$.

*N. D: Not decrease in peak height. SD: Standard deviation 
Table 4: FT-IR peak wave numbers $\left(\mathrm{cm}^{-1}\right)$ changes compared to control (untreated skin) and abdominal hydrated whole skin rat following treatment with different enhancers. (mean $\pm S D, n=3$ )

\begin{tabular}{llllll}
\hline Vehicles & C-H stretching asy & C-H stretching sym & C=0 stretching of lipid ester & Amid I & Amid II \\
\hline Control & $2915.13 \pm 0.2$ & $2840.74 \pm 0.4$ & $1690.2 \pm 1$ & $1642.58 \pm 0.9$ & $1535.9 \pm 0.2$ \\
Eucalyptus & $-2908.58 \pm 0.1$ & $2856.57 \pm 0.1$ & $1725.03 \pm 0.1$ & $1631.07 \pm 0.1$ & $1546.34 \pm 0.1$ \\
Menthol & $2923.39 .13 \pm 0.2$ & $4772.51 \pm 0.1$ & $1758.18 \pm 0.1$ & $1672.45 \pm 0.2$ & $1570.73 \pm 0.2$ \\
Olive & $2594.97 \pm 0.1$ & $2467.6 \pm 0.3$ & $1742.11 \pm 0.2$ & - & - \\
Urea & 250.1 & $1774.9 \pm 0.1$ & - & - \\
\hline
\end{tabular}

SD: Standard deviation, FT-IR: Fourier transform infrared spectroscopy

Table 5: Decrease in mean peak height $( \pm S D)$, compared with control (hydrated skin) of $\mathrm{C}=0$ stretching (Amide I) and $\mathrm{C}-\mathrm{N}$ stretching of keratin (Amide II) absorbance of abdominal hydrated whole skin rat following treatment with different enhancers (Mean $\pm S D, n=3$ )

\begin{tabular}{|c|c|c|c|c|}
\hline \multirow[t]{2}{*}{ Vehicles } & $\begin{array}{l}\mathrm{C}=0 \\
\text { stretching }\end{array}$ & $\begin{array}{l}\text { of } \\
\text { keratin }\end{array}$ & $\begin{array}{l}\text { C-N } \\
\text { stretching }\end{array}$ & $\begin{array}{l}\text { of } \\
\text { keratin }\end{array}$ \\
\hline & Peak height & $\% \mathrm{D}$ & Peak height & $\% \mathrm{D}$ \\
\hline Control & 0.012 & - & 0.414 & - \\
\hline Eucalyptus & 0.002 & $\overline{83.3}$ & 0.008 & $\overline{9} 8.06$ \\
\hline Menthol & 0.392 & Not seen & 0.159 & 61.59 \\
\hline Olive & 0 & 100 & 0 & 100 \\
\hline Urea & 0 & 100 & 0 & 100 \\
\hline
\end{tabular}

SD: Standard deviation

\section{CONCLUSION}

The results obtained indicate that the used permeation enhancers increased the drug permeability through excised rat skin. Different mechanisms including lipid fluidization, disruption lipid structure, and also intracellular keratin irreversible denaturation in SC by eucalyptus oil, olive oil, menthol, and urea are the main probable mechanisms for higher $\mathrm{ER}_{\text {flux }}, \mathrm{ER}_{\mathrm{D}}$, and $\mathrm{ER}_{\mathrm{p}}$ ratios compared with waterskin hydrated.

\section{ACKNOWLEDGMENT}

This paper was derived from the Pharm D thesis (Zarooni, M. No. Gp 95165) for which financial support was provided by Student Research Committee, Ahvaz Jundishapur University of Medical Sciences.

\section{AUTHORS' CONTRIBUTION}

Saadatzadeh \& Salimi designed the experiments.

Zarooni \& Salimi carried out the analysis tests. Saadatzadeh \& Salimi prepared the manuscript.

\section{FUNDING}

This study was financially supported by a research grant from Student Research Committee, Jundishapur University of Medical Sciences, Ahvaz, Iran.

\section{REFERENCES}

1. Salimi A, Moghimipour E, Tavakolbekhoda N. Transdermal delivery of celecoxib through rat skin from various microemulsions. Skin 2013:8:9.

2. Singh P, Roberts MS. Skin permeability and local tissue concentrations of nonsteroidal anti-inflammatory drugs after topical application. J Pharmacol Exp Ther 1994;268:144-51.

3. Ghosh TK, Banja AK. Methods of enhancement of transdermal drug delivery: Part IIA, chemical permeation enhancers. Pharm Tech 1993;18:62-90.

4. Bavarsad N, Akhgari A, Seifmanesh S, Salimi A, Rezaie A. Statistical optimization of Ketorolac -loaded penetration-enhancer vesicles (PEV) for topical delivery. DARU J Pharm Sci 2016;24:7.

5. Kimbrough-Green CK, Griffiths CE, Finkel LJ, Hamilton TA, BulengoRansby SM, Ellis CN, Voorhees JJ. Topical Ketorolac for melasma in black patients: A vehicle-controlled clinical trial. Arch Dermatol 1994;130:727-33.

6. Bavarsad N, Akhgari A, Seifmanesh S, Salimi A, Rezaie A. Statistical optimization of Ketorolac -loaded penetration-enhancer vesicles (PEV) for topical delivery. DARU J Pharm Sci 2016;24:7.

7. Bhatia KS, Gao S, Singh J. Effect of penetration enhancers and iontophoresis on the FT-IR spectroscopy and LHRH permeability through porcine skin. J Controlled Release 1997;47:81-9.

8. Salimi A, Yousefi AA. Analysis method: FTIR studies of $\beta$-phase crystal formation in stretched PVDF films. Polymer Testing 2003;22:699-704.

9. Reed BL, Morgan TM, Finnin BC. Inventors; Monash University, Assignee. Dermal Penetration Enhancers and Drug Delivery Systems Involving Same. United States Patent US 6,299,900; 2001.

10. Salimi A, Hedayatipour N, Moghimipour E. The effect of various vehicles on the naproxen permeability through rat skin: A Mechanistic study by DSC and FT-IR techniques. Adv Pharm Bull 2016;6:9-16.

11. Boncheva M, Damien F, Normand V. Molecular organization of the lipid matrix in intact stratum corneum using ATR-FTIR spectroscopy. Biochim Biophys Acta 2008; 1778:1344-55

12. Moghimipour E, Salimi A, Zadeh BS. Effect of the various solvents on the in vitro permeability of vitamin B12 through excised rat skin. Trop J Pharm Res 2013;12:671-7.

13. Kumar R, Philip A. Modified transdermal technologies: Breaking the barriers of drug permeation via the skin. Trop J Pharm Res 2007;6:663-44.

14. Salimi A, Zadeh BS, Safavi G. Effect of formulation components on the in vitro skin permeation of micro emulsion drug delivery system of piroxicam. Int Res J Pharm Appl Sci 2013;3:152-60.

15. Moghimipour E, Salimi A, Leis F. Preparation and evaluation of Ketorolac microemulsion based on pseudo-ternary phase diagram. Adv Pharm Bull 2012;2:141.

16. Ragno G, Veronico M, Maddalena R, Vetuschi C. Ketorolac assay in cosmetics and pharmaceuticals by carbon phase extraction. J Soc Cosmetic Chem 1996;47:325.

17. Barry BW. Dermatological Formulation: Percutaneous Absorption. New York: Marcel Dekker; 1983.

18. Moser K, Kriwet K, Naik A, Kalia YN, Guy RH. Passive skin penetration enhancement and its quantification in vitro. Eur J Pharm Biopharm 2001;52:103-12.

19. Williams AC, Barry BW. Terpenes and the lipid-protein-partitioning theory of skin penetration enhancement. Pharm Res 1991;8:17-24.

20. Barry BW. Novel mechanisms and devices to enable successful transdermal drug delivery. Eur J Pharm Sci 2001;14:101-14

21. Salimi A, Hedayatipour N, Moghimipour E. The effect of various vehicles on the naproxen permeability through rat skin: A Mechanistic study by DSC and FT-IR techniques. Adv Pharm Bull 2016;6:9-16.

22. Pillai O, Nair V, Panchagnula R. Transdermal iontophoresis of insulin: IV. Influence of chemical enhancers. Int J Pharm 2004;269:109-20.

23. Aqil M, Ahad A, Sultana Y, Ali A. Status of terpenes as skin penetration enhancers. Drug Discov Today 2007;12:1061-7.

24. Williams AC, Barry BW: Penetration enhancers. Adv Drug Deliv Rev 2004;56:603-18

25. Karande P, Mitragotri S. Enhancement of transdermal drug delivery via synergistic action of chemicals. Biochim Biophys Acta 2009; 1788:2362-73.

26. Singh PB, Choudhury PK. Penetration enhancers for transdermal drug delivery of systemic agents. J Pharm Res 2007;6:44-50.

27. Höhne G, Hemminger WF, Flammersheim HJ. Differential Scanning Calorimetry. Berlin - Heidelberg: Springer Science and Business Media; 2013.

28. Yaghmur A, Aserin A, Tiunova I, Garti N. Sub-zero temperature behaviour of non-ionic microemulsions in the presence of propylene 
glycol by DSC. J Thermal Anal Calorimetry 2002;69:163-77.

29. Friese MA, Banerjee S. FT-IR spectroscopy. Surface Analysis of Paper; 1995. p. 119-41.

30. Jackson M, Mantsch HH. The use and misuse of FTIR spectroscopy in the determination of protein structure. Crit Rev Biochem Mol Biol 1995;30:95-120.
31. Dewan A, Liu M, Hartman S, Zhang SS, Liu DT, Zhao C, et al. HTRA1 promoter polymorphism in wet age-related macular degeneration. Science 2006;314:989-92.

32. Salimi A, Noorbakhsh A. Layer by layer assembly of glucose oxidase and thiourea onto glassy carbon electrode: Fabrication of glucose biosensor. Electrochim Acta 2011;56:6097-105. 